\title{
Tabular Representation of Control Action in Active Power Distribution Units for AC Railways
}

\author{
Pavel V. Morozov \\ Theoretical Fundamentals of Electrical Engineering Dept. \\ Novosibirsk State Technical University \\ Novosibirsk, Russia \\ kaftoe@ngs.ru
}

\author{
Yury V. Morozov \\ Theoretical Fundamentals of Radio Engineering Dept. \\ Novosibirsk State Technical University \\ Novosibirsk, Russia \\ sibfrost24@mail.ru
}

\begin{abstract}
Active power distribution is important for AC traction systems where loads change suddenly. It is proposed to use tabular representation of control action in active filters based on power width modulation. Such modulation with control action look-up tables helps to achieve almost zero unbalance between phase currents and voltages in a three-phase primary grid.
\end{abstract}

Keywords-power distribution; look-up table; pulse-width modulation; control; voltage

\section{INTRODUCTION}

Development of data acquisition systems and computers caused appearance of many methods how to present, store and process data in measurement, control and energy conversion systems. Usually an output value is connected with an input values or several input values by a complicated mathematical equation describing some physical properties of a medium between the input and the output. Such equations can take a big amount of computation time. Different approximation methods are analyzed for liquid solidification in [1]. To accelerate computations it is convenient to use tabular approximations of initial dependences. Such approximations help to avoid enormous multiplication and division operations with a floating point. Therefore, tabular approximation is useful for compact description of a conversion factor in a thermal system or an electrical system.

The purpose of the paper is to show that the tabular approximation is useful for pulse-width modulation power converters in active power distribution systems for ac highspeed electric railways. The paper contains a general description of an autotransformer-based traction power system connected to a three-phase primary grid through a singlephase or a Scott transformer. Then an active power distribution multilevel power equalizer based on capacitive accumulators and semiconductor bridges between transformer secondary windings is introduced. The essence of the paper is the power equalizer control block-diagram with a pulse-widthmodulation look-up table. The look-up table is important for power quality optimization [2]. The required levels of higher current and voltage harmonics and unbalance are achieved by selecting pulse-width-modulation sample frequency and the number of semiconductor bridges voltage levels [3]. As far as it is known the voltage higher harmonics and unbalance levels are limited by the demands stated in [4]. Zero current and voltage unbalance can be achieved by selecting some special structures of transformer like a pair of single-phase transformers, a Scott transformer, a Leblanc transformer only if loads at their secondary windings are equal [5].

\section{STATEMENT OF PURPOSE}

The purpose of the investigation provided is to propose a tabular approximation of pulse-width modulation in the power equalizer for active power distribution between secondary windings of the transformer connected to a threephase primary grid. The power equalizer with the tabular approximation pulse-width-modulation control was simulated in Matlab Simulink. The simulation results are presented at the end of the paper.

\section{AUTOTRANSFORMER BASED AC TRACTION POWER SYSTEM WITH THE SCOTT TRANSFORMER DESCRIPTION}

An autotransformer based power supply system for highspeed railways [6] consists of contact wire, feeding wire and a rail system (Fig 1).

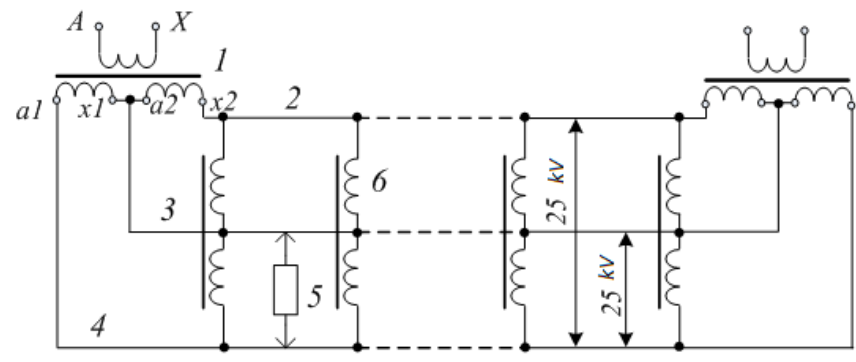

Fig. 1. $2 \times 25 \mathrm{kV}$ ac railway power supply system: 1- single-phase transformer $110(220) \mathrm{kV}, 2$ - feeding wire $50 \mathrm{kV}, 3$ - contact wire $25 \mathrm{kV}, 4$ rail, 5- electric locomotive traction load, 6 - railway autotransformet 50/25 $\mathrm{kV}$

Power quality in a three-phase primary grid is strongly influenced by the connection point transformer structure between a secondary two-phase traction grid and three-phase primary grid. The transformer in the connection point between the secondary traction grid and primary three-phase grid can consists of two single-phase transformers, two three-phase transformers, Woodbridge transformer, combination of a single phase transformer and three-phase transformer, etc. The 
pairs of single-phase transformers and three-phase transformer cannot provide currents balance even if traction loads are equal. The combination of three-phase and single phase transformer or Woodbridge transformer of two three-phase transformers are able to provide zero current unbalance for equal traction load when one transformer is overloaded and another one is unloaded. Hence one transformer will degrade faster than the another one. The Scott connected transformer is free of the considered above disadvantages.

The Scott connected transformer provides the total currents and voltages balance in a three-phase primary grid only if loads at its secondary side are equal because only these conditions help to support 90 degree phase shift between currents in secondary windings. Currents equality and orthogonality permit to distribute active power between Scott transformer windings in such a way that currents unbalance in a primary three-phase grid is almost zero. The structure of the Scott transformer allows to support three-phase grid current and voltage zero unbalance only if traction loads at its secondary side are the same when there is no trains on both paths the railway or there are similar trains in the traction or running-out mode. However, in practice one train can be in the traction mode while another one is in the running out-mode. A train can also occur at one path when there is no train at another one. Therefore, even the Scott transformer cannot provide zero unbalance in such condition. It is necessary to connect a power equalizer in parallel with the Scott transformer secondary windings based on two bridge converters and capacitors between them [7]. Te capacitors with bridges help to support the balance of active power at the Scott transformer secondary windings. They take extra power from one winding and transfer it into another one.

\section{MULTILEVEL ACTIVE POWER EQUALIZATION PRINCIPLE FOR SCOTT TRANSFORMER SECONDARY WINDINGS}

The power equalizer connected between the Scott transformer secondary windings is shown in Fig. 2, where $u_{s l}$ and $u_{s 2}$ are the voltages at the Scott transformer secondary windings, $\mathrm{M}_{11}, \mathrm{M}_{12}, \mathrm{M}_{13}, \mathrm{M}_{14}, \mathrm{M}_{21}, \mathrm{M}_{22}, \mathrm{M}_{23}, \mathrm{M}_{24}$, - are the bridges made of controllable semiconductor elements such as GTO thyristors or IGBT transistors.

As the voltages at the Scott transformer secondary windings are usually about $50 \mathrm{kV} \sigma$, it is preferable to implement the cascade connection of four multilevel bridges with the midpoint [8]. The transformation ratios of the coupling transformers are equal to 1:4. If the Scott transformer secondary winding voltage values is equal to $50 \mathrm{kV}$, then each bridge voltage drop is $12.5 \mathrm{kV}$. The coupling transformer leakage inductance substitutes reactor inductance.

The capacitors battery is implemented with the midpoint (Fig. 3). The midpoint helps to generate the five voltage levels $-2 U_{C},-U_{C}, 0, U_{C}, 2 U_{C}$.

Thyristors switch frequency should be as high as possible to separate higher harmonics from useful signal harmonics. However it is limited by thyristors materials features.

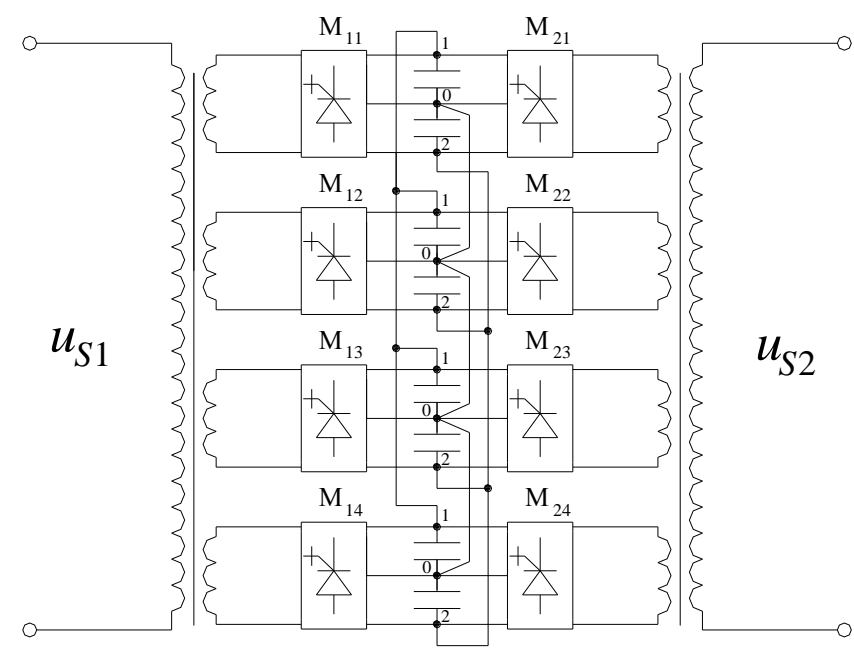

Fig. 2. Multilevel power equlizer with coupling transformers

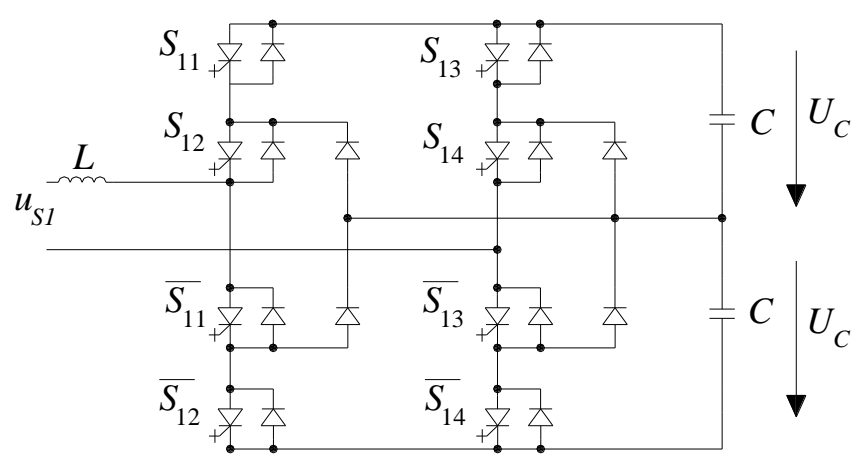

Fig. 3. Power eqalizer fragment

This frequency can be reduced by means of the multilevel pulse-width-modulation based on four reference triangular periodic signals with the phase shifts $0,90,180,270$ degrees. This kind of modulation helps to find an optimal combination of switch frequency and voltage levels number.

Quality of the Scott transformer secondary winding current depends on power equalizer thyristors control algorithm.

The control block-diagram for pulse-width-modulation signal generation is stated in Fig. 4.

The current error signal is compared with the sequences of generated triangular impulses (GTI) by the comparators CM1CM2. If the error is more than a reference signal a comparator outputs " 1 " otherwise " 0 ". The combinations of these zeros and ones correspond to certain capacitors voltages. Such relations are accepted to be a look-up table approximation of capacitors voltages. These voltages effect to transformer currents. Each voltage is generated by a sum of comparisons results at the comparators outputs $\mathrm{N}$ transformed into states of the switches $S_{j 1}, S_{j 2}, S_{j 3}, S_{j 4}$ and their inversions where $j$ is the number of the Scott transformer secondary winding (Table 1). 


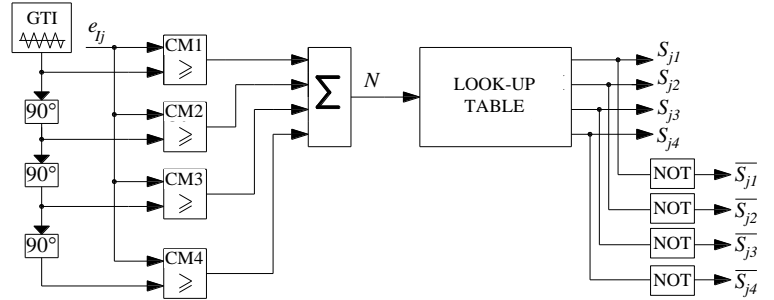

Fig. 4. Multilevel pulse-width-modulation generation block-diagram

TABLE I. MULTILEVEL PULSE-WIDTH MODULATION LOOK-UP TABLE

\begin{tabular}{|c|c|c|c|c|c|}
\hline $\mathbf{N}$ & $\mathbf{S}_{\mathbf{j} \mathbf{1}}$ & $\mathbf{S}_{\mathbf{j} \mathbf{2}}$ & $\mathbf{S}_{\mathbf{j} \mathbf{3}}$ & $\mathbf{S}_{\mathbf{j} \mathbf{4}}$ & $\mathbf{U}_{\mathbf{1 j}}$ \\
\hline 0 & 0 & 0 & 1 & 1 & $-2 U_{C}$ \\
\hline 1 & 0 & 0 & 0 & 1 & $-U_{C}$ \\
\hline 2 & 0 & 0 & 0 & 0 & 0 \\
\hline 3 & 0 & 1 & 0 & 0 & $+U_{C}$ \\
\hline 4 & 1 & 1 & 0 & 0 & $+2 U_{C}$ \\
\hline
\end{tabular}

\section{SimUlation RESUlTS}

The multilevel pulse-width-modulation in the Scott transformer power equalizer was simulated in Matlab Simulink.

Fig. 5, Fig. 6 and Fig. 7 contain the results of simulation of the scheme in Fig. 4 for the model voltages at the transformer windings $u_{S 1} t=500 \cdot \sin \omega t, u_{S 2} t=500 \cdot \cos \omega t$ if the reactor inductivity is $L=1.5 \mathrm{mH}$ and capacitors battery total capacity is $10000 \mu \mathrm{F}$. Such battery consists of self-recovery capacitors made of polypropylene film metalized by the mix of zinc and aluminum. The self-recovery effect is provided by metal evaporation around a burst damaged place providing high reliability.

Fig. 7 shows that that the power equalizer provides currents equality in transformer windings and the phased shift 90 degrees between them when the load current $i_{Z 1}$ abruptly changes. The load such an electric train appears in parallel with the voltage $U_{S 1}$. The worst case is when one of load currents is equal to zero.

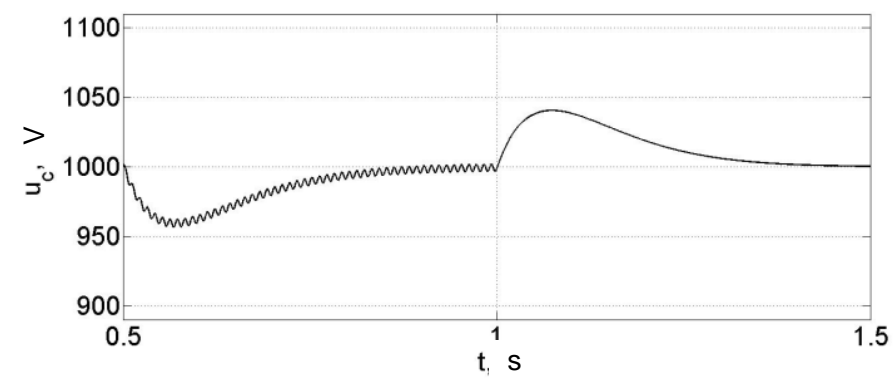

Fig. 5. Capacitor voltage

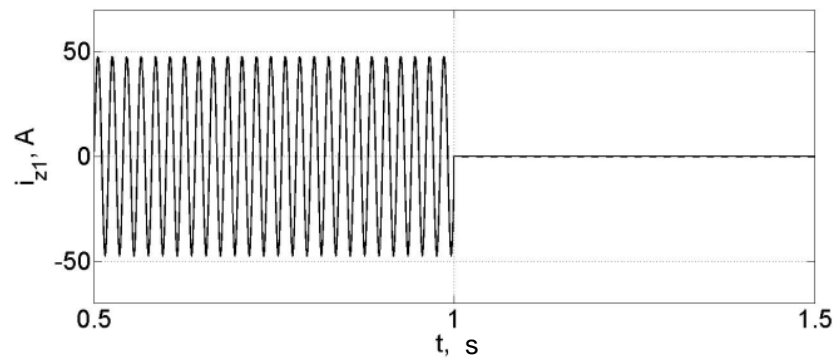

Fig. 6. Traction load current

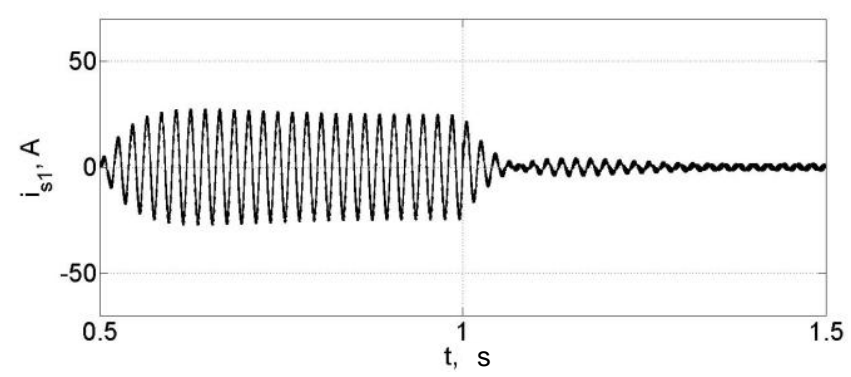

a)

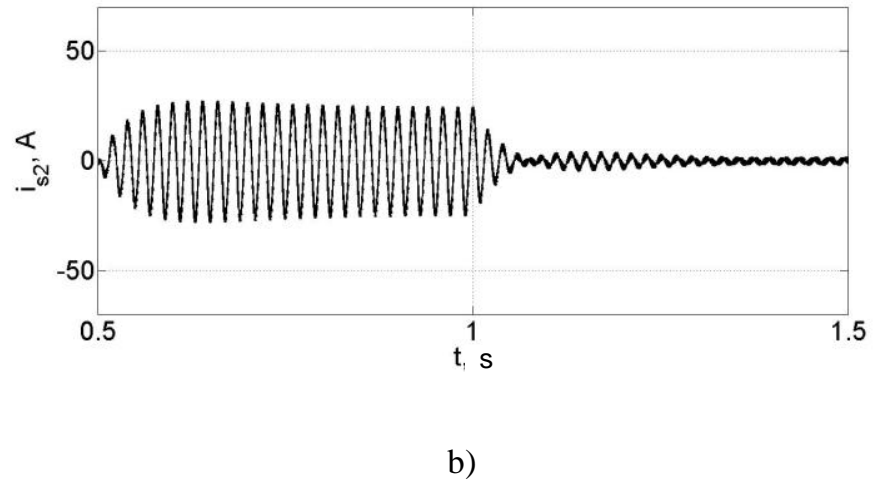

Fig. 7. Currents in trasformer secondary windings

Fig. 5 contains the capacitor voltage, which is changing exponentially with some rippling. Transient process time is no more than 0.5 s. Fig. 6 demonstrates the worst case of load changing. One load appears suddenly and then disappears while there is no another load. Fig. 7 shows the power equalizer capability to distribute uniformly active power between phases providing almost zero unbalance. Application of the pulse-width modulation look-up table helps to support very small phase current ripple and very low level of higher harmonics.

The voltage drop at the capacitors is supported to be zero by the filters pulse-width modulation control [9]. The unbalance factor dependence on pulse-width modulation frequency and voltage levels number at each side of the transformer obtained by simulation in Matlab Simulink is stated in Table II. The unbalance factor decreases with 
increase of pulse-width modulation frequency and the filters number. The underlined value $1.9 \%$ is found to be optimal. It corresponds to the minimal as possible pulse-width modulation frequency $3 \mathrm{kHz}$ and voltage levels number 4 . At the same time, this value is maximal one satisfying to Russian standards power quality requirements that unbalance should be less than $2 \%$ [4].

Fig. 6 shows the voltage unbalance factor dependence on formed voltage levels number for several pulse-width modulation frequency values.

TABLE II. POWER EQUILIZER Unbalance

\begin{tabular}{|l|l|l|l|l|l|}
\hline $\begin{array}{r}\text { Voltage levels } \\
\text { Number } \\
\boldsymbol{P W M} \text { frequency, } \\
\boldsymbol{k H z}\end{array}$ & $\mathbf{1}$ & $\mathbf{2}$ & $\mathbf{3}$ & $\mathbf{4}$ & $\mathbf{5}$ \\
\hline $\boldsymbol{1}$ & $5,0 \%$ & $4,0 \%$ & $3,0 \%$ & $2,3 \%$ & $2,2 \%$ \\
\hline $\mathbf{2}$ & $4,5 \%$ & $3,9 \%$ & $2, \% 8$ & $2,1 \%$ & $2,1 \%$ \\
\hline $\mathbf{3}$ & $4,2 \%$ & $4,1 \%$ & $2,5 \%$ & $\underline{1,9 \%}$ & $1,8 \%$ \\
\hline $\mathbf{4}$ & $4,0 \%$ & $3,5 \%$ & $2,3 \%$ & $1,6 \%$ & $1,5 \%$ \\
\hline $\mathbf{5}$ & $3,5 \%$ & $3,0 \%$ & $2,1 \%$ & $1,5 \%$ & $1,4 \%$ \\
\hline
\end{tabular}

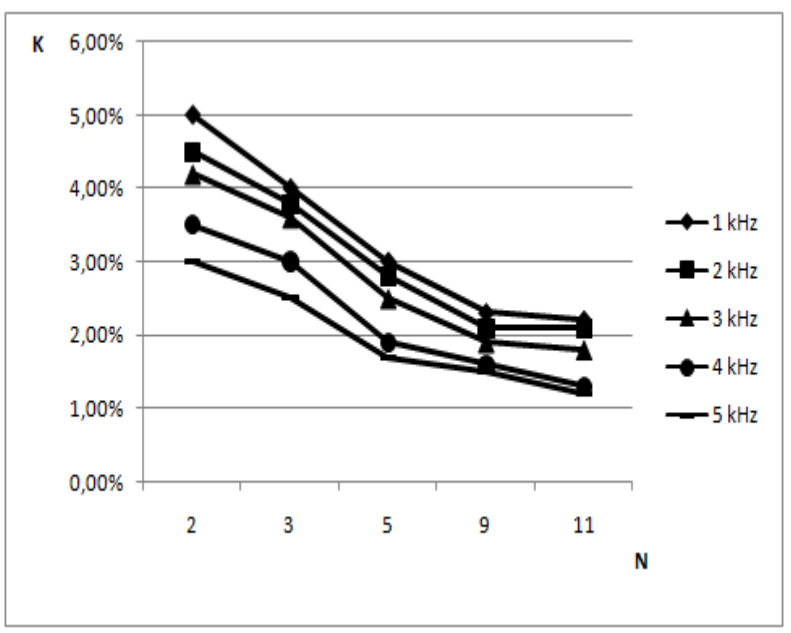

Fig. 8. Unbalance factor dependence on the generated voltage levels number

\section{DISCUSSION OF RESULTS AND THEIR PERSPECTIVES}

The simulation results stated in Fig. 8 demonstrate that it is possible to select the domain of pulse-width modulation frequency and the voltage level number combinations with the unbalance factor no more that $2 \%$ permitted by the standard [4]. The variant providing the minimal number of voltage levels and pulse-width modulation frequency is the most preferable. As far as we know, less voltage levels number and pulse-width modulation frequency leads to decrease of the elements number and power consumption. As it follows from Fig. 8, five voltage levels and $4 \mathrm{kHz}$ pulse-width modulation frequency is the optimal combination with respect to standard demands.

The proposed power equalizer control based on the lookup table has a perspective of the practical application at the high-level segment of the power system where a $110 \mathrm{kV}$ power grid is connected to a $220 \mathrm{kV}$ power grid [10].
The Scott transformer-based circuit application in the point of the high-speed railway power supply system connection to a three-phase grid requires replacement of existing transformers in all connection points. As any long segment of an ac power system such as an autotransformer-based traction grid $2 \times 25 \mathrm{kV}$ has from 10 to 20 connection points transformers replacement can be non-value-added. Especially it concerns segments where the three-phase grid consists of two voltage steps: $220 \mathrm{kV}$ and $110 \mathrm{kV}$. Usually $110 \mathrm{kV}$ and $220 \mathrm{kV}$ steps are connected by three-phase autotransformers.

To keep $2 \times 25 \mathrm{kV}$ connection points unchanged the threephase transformers between $110 \mathrm{kV}$ and $220 \mathrm{kV}$ grids are proposed to be replaced by a three-to-two or three-to-four Scott transformers. For instance, if a $110 \mathrm{kV}$ grid has two connection points with a $220 \mathrm{kV}$ grid and five connection points with $110 / 55 \mathrm{kV}$ substations to supply the $2 \times 25 \mathrm{kV}$ traction power system, then it is enough to change only two existing transformers by Scott ones. Additionally, the Scott transformer application for feeding the $110 \mathrm{kV}$ grid from the $220 \mathrm{kV}$ grid permits further using single-phase transformers. The main advantage of these transformers is zero additional phase shift of voltage at the secondary side relative to voltage at the primary side. It is also possible to save reserve transformers in each substation to replace any damaged singlephase transformer. Therefore the $110 \mathrm{kV}$ grid becomes twophase one with $90 \mathrm{deg}$ phase shift between phase voltages. Hence if $110 \mathrm{kV}$ phases are loaded equally, then complete current symmetry is provided in the three-phase $220 \mathrm{kV}$ grid.

As it follows from the analysis of the $2 \times 25 \mathrm{kV}$ power system segments there are some plants and settlements with single-phase and three-phase power consumers. Single-phase loads including the most of household appliances have no features to prevent their connection to one phase of the twophase grid. At the same time three-phase consumers such as oil pump motors demand the two-phase voltage system to three-phase one. This problem is solved because it is possible to connect two phases of the Scott transformer to the power grid and to connect three phases to a consumer.

If the Scott transformer is used instead of single-phase transformers, the Scott transformer both secondary windings should be grounded.

To improve electrical energy transmission reliability you should replace a three-phase symmetrical system to four-phase one where phase shift between any adjacent voltages or currents is 90 degrees. The Scott transformers are included between $110 \mathrm{kV}$ and $220 \mathrm{kV}$ power grids to make a four-phase power system saving existing single-phase transformers at the most of substations.

The four-phase system is formed by two parallel Scott transformers (Fig. 9). Begins of the secondary windings of one transformer are connected to corresponding phase wires while begins of the secondary windings of other transformer are grounded. Each transformer compounds its own two-phase system with $90 \mathrm{deg}$ phase shift. One of the mentioned twophase systems has $180 \mathrm{deg}$ shift relative other one. Hence we have the four-phase system with voltage phase shifts $0 \mathrm{deg}, 90$ $\mathrm{deg}, 180 \mathrm{deg}$ and $270 \mathrm{deg}$. 


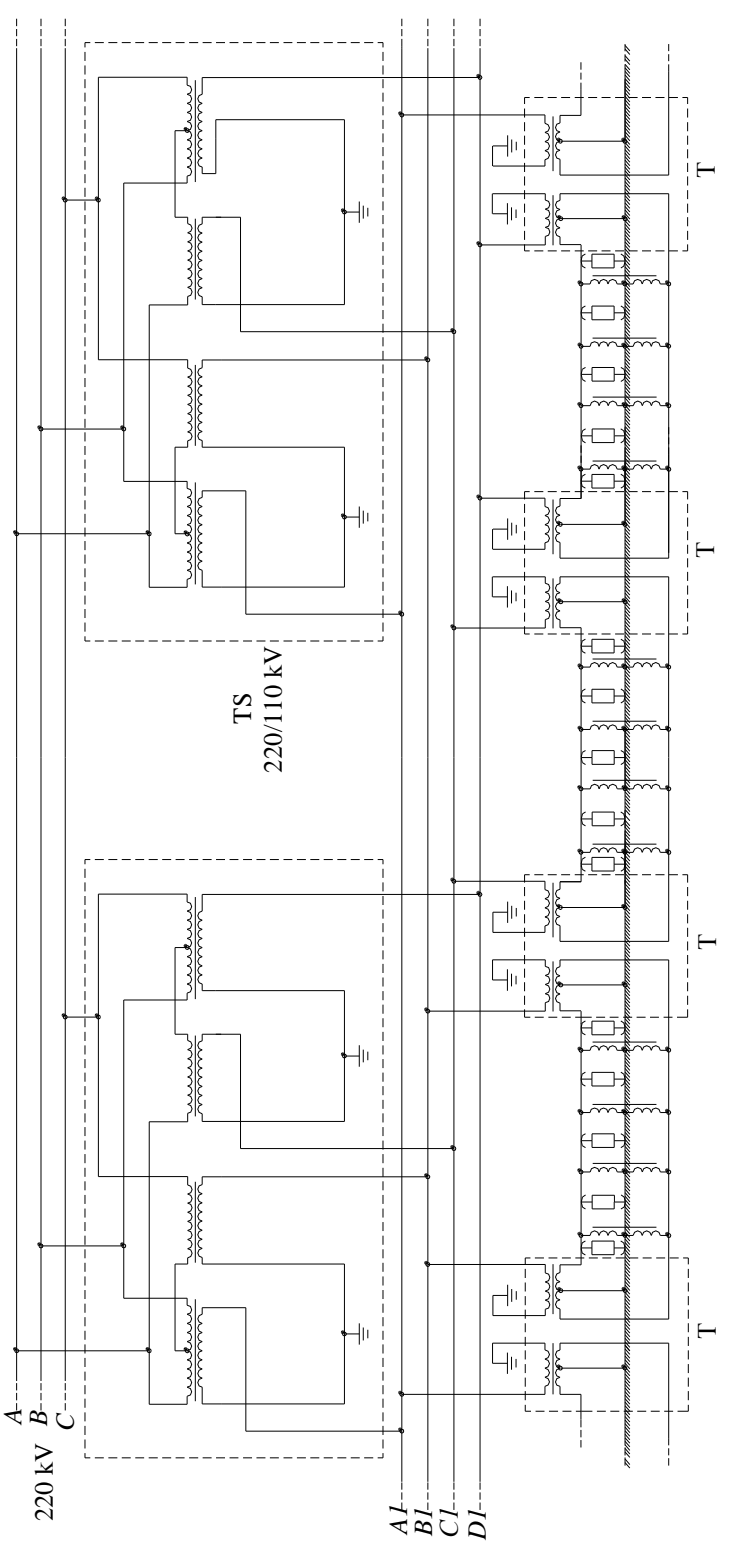

Fig. 9. Unbalance factor dependence on generated voltage levels number

Four phase lines should be placed at towers as two balanced two-phase systems. Currents or voltages in these two-phase systems should have opposite phase shifts to provide line wires inductance to be compensated.

Operation of such four phase line can be supported by the proposed equalizer with pulse-width modulation based on the look-up table when it is necessary distribute high voltages among many bridges of semiconductor switch elements.

\section{CONCLUSION}

Therefore, the optimal control quality in the semiconductor power equalizer of the Scott transformer secondary windings is provided by the look-up table that supports five voltage levels at not very high pulse-width-modulation frequency values. The power equalizer with the look-up table based control algorithm helps to achieve almost zero current and voltage unbalance in a three-phase primary grid because to equal active power distribution between transformer secondary windings.

Power equalizer look-up table based control simulation in Matlab Simulink permitted to find optimal combination of pulse width modulation frequency and voltage levels number with respect to the standard demands on three-phase grid voltage unbalance degree.

The Scott circuit with look-up table based power equalizer is the mostly preferable power converter structure to provide zero current unbalance when both primary and secondary windings are loaded equally. The Scott circuit applied as the connection point between $110 \mathrm{kV}$ and $220 \mathrm{kV}$ power grids makes it possible to create the $110 \mathrm{kV}$ two-phase power grid with existing single-phase transformer-based substations. In spite of the Scott transformer is more expensive than a pair of single-phase transformers it is more reliable because there is no phase overloads. The power equalizer parameters are found to make transformer to meet standard requirements.

\section{REFERENCES}

[1] R. Dyja, E. Gawronska, A. Grosser, P. Jeruszka, N. Sczygiol "Estimate the impact of different hear capacity approzimaiton methods on the numerical results during computer simulation of solidification", World Congress on Engineering and Computer Science Proceedings: Transactions on Engineering Tehcnologies, 2015, pp 1-14.

[2] S. Almer, S. Marieholtz, M. Morari "Optimal sampled data control of PWM systems using piecewise affine approximation", Proceedings of $49^{\text {th }}$ IEEE Conference on Decision and Control, 15-7 Dec. 2010, pp. 2143-2148.

[3] A. Leedy, R. Nelms "Harmonic Analysis of a Three-Level Sinusoidal PWM Inerter Using the Method of Pulse Pairs", Proceedings of IEEE International Symposium on Industrial Electronics, 9-3 July 2006, pp. 2608-2613.

[4] V.V. Nikiforov "New Standard of electric power quality. Main positions and differences from GOST 13109-97", Novosti Elecrotechniki, 2011. Vol. 3, pp. 15-17.

[5] G. Firat, G. Yang, H. Ali Hussain Al-Ali "A comparative study of different transformer connections for railway power supply mitigation of voltage unbalance", Proceedings of 10th International Conference on Advances in Power System Control, Operation and Management, 2015, pp. 1-6.

[6] D. Proto, Impact of Innovation Technology on Complex Systems: the Electrified Railway Supply System, Napoli, 2004, p. 130.

[7] P. V. Morozov "Controllable converters for high-speed railways traction transformers", Actual Problems of Electronic Instrument Engineering (APEIE-2016), 3-6 Oct. 2016, Novosibrsk, NSTU, 2016, Vo. 1, Part 3, pp. $52-54$

[8] G.G.Terbobri, M.F Saidon, M.S.Khanniche, "Trends of Real Time Controlled Active Power Filters", Power Electronics and Variable Speed Drives, 18-19 September 2000, Conference Publication No. 475, P. 410415.

[9] M. Boost, P. Ziogas, State-of-the-art carier PWM techniques: a critical evaluation, IEEE Transactions on Industry Applications, 1988, Vol. 24, No. 2, pp. 271-280.

[10] P.V. Morozov, Yu. V. Morozov "N-phase loads agreement with threephase grids by transformers with power equilizers", 11 International forum on strategic technology (IFOST 2016): proc., Novosibirsk, 1-3 June 2016, NSTU, 2016, Part 2, pp. 16-19. 